\title{
Exigência protéica de juvenis de tambaqui (Colossoma macropomum) após privação alimentar
}

\author{
Luciana SANTOS ${ }^{1}$, Manoel Pereira FILHO $^{2}$, Cássia SOBREIRA ${ }^{3}$, Daniel ITUASSÚ ${ }^{5}$, Flávio Augusto Leão da \\ FONSECA ${ }^{4}$ \\ RESUMO
}

O objetivo deste trabalho foi avaliar a exigência protéica de juvenis de tambaqui (Colossoma macropomum) após a privação alimentar. Os peixes $(50,3 \pm 0,26 \mathrm{~g})$ foram submetidos a quatro rações isoenergéticas com diferentes concentraçóes protéicas (28, 32, 36 e 40\% proteína bruta) e dois regimes alimentares (com privação e sem privação) durante 60 dias. O delineamento experimental foi inteiramente casualizado, em esquema fatorial $4 \mathrm{x} 2$, em triplicata. Avaliaram-se os parâmetros de qualidade de água e de desempenho no $1^{\circ}, 15^{\circ}$ e $60^{\circ}$ dia de experimento. Os parâmetros da qualidade da água permaneceram dentro dos padróes de cultivo. Não houve mortalidade nos tratamentos testados. Foram observados diferenças entre os tratamentos para os índices de desempenho analisados: taxa de crescimento específico, eficiência alimentar, consumo diário de ração, consumo de proteína bruta, taxa de eficiência protéica e ganho de peso relativo, com exceção do índice hepatossomático. Houve hiperfagia, indicando a existência de crescimento compensatório. Os peixes realimentados com 36\% proteína bruta tiveram incremento no teor de gordura visceral e maior deposição de proteína corporal. Estes resultados explicam uma melhora nos dados de ganho de peso, duração da hiperfagia, taxa de crescimento e eficiência alimentar. A privaçáo alimentar não influencia a exigência protéica em juvenis de tambaqui.

PALAVRAS-CHAVE: Colossoma macropomum; crescimento compensatório; nutrição de peixes; piscicultura

\section{Protein requirement of tambaqui juveniles (Colossoma macropomum) after feed deprivation}

\section{ABSTRACT}

The aim of this work was evaluate protein requirement of tambaqui (Colossoma macropomum) juveniles after feed deprivation. During 60 days, fish $(50,3 \pm 0,26 \mathrm{~g})$ were fed on four isoenergetics diets with different protein content $(28,32,36$ and $40 \%$ crude protein) at two feeding regimes (with and without feed deprivation) under completely random factorial design (4x2) in triplicate. Water quality parameters and performance index were evaluated at $1^{\circ}, 15^{\circ}$ and $60^{\circ}$ days. Water quality parameters were kept at normal fish cultivation patterns. No mortality in the tested treatments. There were observed differences among treatments for performance indexes analyzed: growth rate, feed efficiency, daily feed consumption, crude protein consumption, efficiency protein rate and relative weight gain, except for hepatosomatic index. Hyperfagia was detected indicating the occurrence of compensatory growth. Fat content and body protein deposition increased in fishes refed on 36\% of crude protein. These results explain some data observed belong the experiment like the increase of weight gain, of the hyperfagia time extension, of the growth rate and of the feed efficiency. Therefore those fish shows increase on weight gain, hyperfagia time, growth rate and feed efficiency. There is no influence of feed deprivation on protein requirement tambaqui juveniles.

KEYWORDS: Colossoma macropomum; compensatory growth; fish nutrition; fish culture

\footnotetext{
${ }^{1}$ Instituto Nacional de Pesquisas da Amazônia. E-mail: lunacarioca@gmail.com

2 In memorian.

${ }^{3}$ Universidade Federal do Amazonas. E-mail: cassiacbs@yahoo.com.br

${ }^{4}$ Instituto Federal do Amazonas. E-mail: guto77@gmail.com

${ }^{5}$ Instituto de Proteção Ambiental do Amazonas. E-mail: dituassu@yahoo.com.br
} 


\section{INTRODUÇÃO}

A Amazônia possui grande potencial para criação de peixes, com recursos hídricos abundantes, clima favorável o ano todo, grande diversidade de espécies valorizadas no mercado e oferta de alevinos das principais espécies (Ono, 2005).

O tambaqui (Colossoma macropomum Cuvier, 1818) é uma das principais espécies cultivadas na Amazônia. Deve-se a isso suas qualidades como onivoria, rusticidade e crescimento rápido (Araújo-Lima \& Goulding, 1998), além de fácil aceitação às raçôes artificiais e adaptação à criação em cativeiro. Uma qualidade primordial é a consistência, bem como o sabor de sua carne muito apreciada pelo consumidor. Esses atrativos lhe conferem um alto valor comercial e importância para a economia regional (Val \& Honczaryk, 1995).

Um dos fatores que garantem a ótima produtividade da piscicultura está relacionado à dieta (Pezzato, 2005). A proteína é um macronutriente essencial na dieta e para o crescimento do peixe. Por representar o mais alto custo alimentar, a sua exigência é priorizada em estudos nutricionais. O preço da ração está diretamente ligado ao teor de proteína, e a alimentaçấo dos peixes pode representar entre $60-70 \%$ dos custos de produçáo (Rotta, 2002).

O crescimento compensatório é uma estratégia bem documentada usada para enfrentar o problema do alto custo de produção dos peixes, podendo ser empregado para melhorar sua taxa de crescimento e ao mesmo tempo diminuir os custos de produção (Hornick et al., 2000).

Este termo refere-se à capacidade do animal para o crescimento mais rápido do que o normal após um período de restrição ou privação alimentar, recuperando o peso original ou aumentando a taxa de crescimento (Jobling et al., 1993a; Nicieza \& Metcalfe, 1997).

Na piscicultura, a exploraçáo adequada desta prática pode resultar em melhoria na produçáo, com aumento na taxa de crescimento, eficiência alimentar e redução do custo com alimentação e mão-de-obra (Wang et al., 2000; Maclean \& Metcalfe, 2001).

Existem poucas informaçôes sobre as alterações das exigências nutricionais dos peixes durante o crescimento compensatório. A maioria dos estudos refere-se a peixes de clima temperado (Souza et al., 2000a; Xie et al., 2001) com poucos relatos para espécies tropicais. Um desses estudos demonstrou que o tambaqui exibiu a compensação do crescimento total e maior deposição de proteína corporal em dois meses, quando submetido à privaçáo de 14 dias, enquanto em 21 e 28 dias de privação não houve crescimento compensatório (Ituassú et al., 2004).

No entanto, para melhorar as taxas de produção do tambaqui quando submetido à privação, é necessário conhecer melhor suas exigências nutricionais para maximizar o potencial de crescimento do peixe, uma vez que mudanças nas taxas de crescimento após privação alimentar podem alterar suas exigências nutricionais para encontrar a demanda necessária para o crescimento (Gaylord \& Gatlin III, 2001).

Considerando que as exigências de proteína podem ser elevadas para suportar o maior crescimento observado durante a compensaçáo do ganho de peso, são necessários maiores estudos para avaliar a melhor relaçáo energia/proteína para esse manejo.

O objetivo deste trabalho foi avaliar a exigência protéica de juvenis de tambaqui após a privação alimentar.

\section{MATERIAL E MÉTODOS}

O experimento foi realizado na Coordenação de Pesquisa em Aqüicultura (CPAQ) do Instituto Nacional de Pesquisa da Amazônia - INPA, localizado na cidade de Manaus, Brasil. A duraçáo do experimento foi de 60 dias, realizado de 28 de outubro a 28 de Dezembro de 2006.

Juvenis de tambaqui ( $\mathrm{n}=384 ; 50,32 \pm 0,26 \mathrm{~g}$ ) foram homogeneamente estocados em 24 tanques de polietileno com volume útil de $200 \mathrm{~L}$, mantidos em sistema aberto e abastecidos com água de poço artesiano a vazão de $0,5 \mathrm{~L}$ por minuto.

O experimento foi conduzido em delineamento inteiramente casualizado, em esquema fatorial (4x2), com oito tratamentos resultantes da combinação de quatro raçóes isoenergéticas, com diferentes concentraçôes de proteínas (28, 32, 36 e 40\% de proteína bruta) e dois regimes alimentares (com privação e sem privação alimentar), com três repetiçôes. O período de privação alimentar foi de 14 dias (Ituassú et al., 2004).

Os peixes foram alimentados manualmente, duas vezes ao dia (9 e 17h) até a saciedade aparente. Os tratamentos sem privação receberam as raçóes experimentais durante todo experimento (60 dias). Os peixes dos tratamentos com privação alimentar foram realimentados, a partir do décimo quinto dia até o final do experimento. Os valores dos itens alimentares foram balanceados de acordo com a concentraçấo de proteína bruta estabelecida neste trabalho. A formulação das raçóes encontra-se na Tabela 1.

Os seguintes parâmetros de qualidade da água dos tanques foram monitorados diariamente: $\mathrm{pH}$, temperatura $\left({ }^{\circ} \mathrm{C}\right)$, condutividade elétrica $\left(\mathrm{mS} \mathrm{cm}^{-2}\right)$ e oxigênio dissolvido $\left(\mathrm{mg} \mathrm{L}^{-1}\right)$ por multiparâmetro digital YSI $65(\mathrm{pH})$ e 85 (temperatura, condutividade e oxigênio).

Os índices zootécnicos avaliados foram: taxa de crescimento específico, TCE $=100[\ln$ massa final $(\mathrm{g})$ - ln massa inicial (g)] $/$ dias; eficiência alimentar, $(\mathrm{EA})=100$ [ganho de peso $(\mathrm{g}) /$ quantidade de ração ingerida $(\mathrm{g})$ ]; consumo diário de ração, $(\mathrm{CDR})=100[$ (quantidade de ração $(\mathrm{g}) /$ biomassa de peixe 
Tabela 1 - Formulação das dietas experimentais com diferentes relações energia/proteína para juvenis de tambaqui (Colossoma macropomum).

\begin{tabular}{lcccc}
\hline \multirow{2}{*}{ Ingredientes } & \multicolumn{4}{c}{$\begin{array}{c}\text { Formulação das Dietas Experimentais } \\
\text { por Nível de Proteína Bruta (\%) }\end{array}$} \\
\cline { 2 - 5 } & T 28 & T 32 & T 36 & T 40 \\
\hline Farelo de soja & 38,0 & 42,2 & 45,0 & 53,0 \\
\hline Farelo de trigo & 19,0 & 19,0 & 15,0 & 11,0 \\
\hline Milho moído & 37,2 & 28,0 & 23,0 & 17,0 \\
\hline Farinha de peixe & 4,0 & 7,5 & 12,9 & 14,8 \\
\hline Óleo de soja & 1,0 & 2,5 & 3,3 & 3,4 \\
\hline Suplemento vitamínico e mineral & 0,8 & 0,8 & 0,8 & 0,8 \\
\hline Total & 100 & 100 & 100 & 100 \\
\hline Proteína bruta (PB) & 28,2 & 31,9 & 36,0 & 40,0 \\
\hline Energia digestível (ED) & 3.249 & 3.338 & 3.407 & 3.402 \\
\hline ED/PB (kcal/g) (j) & 11,5 & 10,5 & 9,5 & 8,5 \\
\hline
\end{tabular}

(g))/dias]; eficiência alimentar $(\mathrm{EA})=100$ [ganho de peso $(\mathrm{g}) /$ quantidade de ração ingerida (g)]; consumo diário de ração, $(\mathrm{CDR})=100[$ (quantidade de ração $(\mathrm{g}) /$ biomassa de peixe $(\mathrm{g})) /$ dias]; consumo de proteína bruta, $(\mathrm{CPB})$ = consumo de alimento $\mathrm{x}$ teor de proteína bruta/tempo; taxa de eficiência protéica, $($ TEP $)$ = ganho de peso $(\mathrm{g}) /$ proteína consumida $(\mathrm{g})$; ganho de peso relativo $(\% \mathrm{GPR})=100$ [peso final $(\mathrm{g})-$ peso inicial (g)/peso inicial (g)]; índice hepatossomático, (IHS) = 100 [massa do fígado $(\mathrm{g}) /$ massa do peixe $(\mathrm{g})$ ].

Para o acompanhamento desses índices zootécnicos foram realizadas três biometrias em todos os peixes (no início do experimento, no $15^{\circ}$ dia e ao final do experimento). Ao final do experimento foi realizada a remoçáo do fígado de cinco animais de cada unidade experimental para a obtençáo do índice hepatossomático.

A composição da carcaça dos animais foi mensurada no início do experimento $(\mathrm{n}=10)$ e ao final $(\mathrm{n}=3)$, em cada unidade experimental, para a análise em triplicata dos teores de umidade, proteína bruta, cinzas e extrato etéreo das carcaças, segundo metodologia descrita pela Association of Official Analytical Chemists - A.O.A.C (1997).

Para o acompanhamento desses índices zootécnicos foram realizadas três biometrias em todos os peixes (no início do experimento, no $15^{\circ}$ dia e ao final do experimento). Ao final do experimento foi realizada a remoção do fígado de cinco animais de cada unidade experimental para a obtenção do índice hepatossomático. A composição da carcaça dos animais foi mensurada no início do experimento $(n=10)$ e ao final ( $\mathrm{n}=3$ ), em cada unidade experimental, para a análise em triplicata dos teores de umidade, proteína bruta, cinzas e extrato etéreo das carcaças.

As variáveis de qualidade da água, índices zootécnicos e análise da carcaça foram analisadas por ANOVA twoway $(p<0,05)$. As variáveis que apresentaram diferenças significativas tiveram suas médias comparadas pelo teste de Tukey, a 5\% de probabilidade (Zar, 1996). As análises dos dados forma feitas pelo aplicativo estatístico Bioestat 5.0 (Ayres et al., 2007).

\section{RESULTADOS E DISCUSSÃO}

Não houve mortalidade nos tratamentos testados. Os intervalos das variáveis de qualidade de água definidos para peixes tropicais (Kubitza, 2003) foram compatíveis com as variáveis monitoradas durante o experimento indicando boas condiçôes da qualidade da água.

A Tabela 2 mostra variaçóes nos valores de oxigênio dissolvido e condutividade elétrica, que podem ser atribuídas ao período de privação pelo qual os peixes passaram, confirmando que os tanques da privaçáo, por terem menor produçáo e liberação de matéria orgânica de origem fecal, e por náo apresentarem sobras de ração na água, levou à diminuição do consumo de oxigênio pelos peixes e a menor condutividade elétrica nos tanques.

No período de realimentação, mostra diferenças somente nos valores de $\mathrm{pH}$ e condutividade elétrica, que podem ser atribuídas pelas diferentes raçóes fornecidas, aumentando a concentraçáo de sais nos tanques conforme o aumento do nível protéico. Esses resultados encontram-se na Tabela 3.

Aos quinze dias de experimento (período de privação alimentar) houve interação significativa entre o fator concentração de proteína na ração e o fator regime alimentar para as variáveis: peso, taxa de crescimento específico e o ganho de peso relativo. A taxa de crescimento específico e o ganho de peso relativo apresentaram diferenças $(\mathrm{p}<0,05)$ entre os tratamentos. Houve perda de peso dos peixes no regime de privação (média de 2,36g) e o ganho de peso no regime sem privação alimentar, apresentando um intervalo de ganho de aproximadamente $(14,13-22,72 \mathrm{~g})$. Foi observado que a medida que aumenta os níveis protéicos, maiores são as TCE e GPR\% dos peixes (Tabela 4).

Segundo Weatherley \& Gill (1987), durante o jejum os processos essenciais e vitais são mantidos por meio de reservas energéticas endógenas, resultando em perda de peso. Este fato acontece em vários órgãos, especialmente no fígado, o qual desempenha papel central no metabolismo (síntese de glicogênio) (Souza et al., 2000a). Algumas espécies de peixes preservam os estoques de glicogênio no fígado, enquanto são mobilizadas grandes quantidades de lipídeos. Já outras espécies, os estoques de glicogênio são conservados, enquanto 
Tabela 2 - Oxigênio dissolvido (OD), temperatura (T), condutividade (C) e pH da água, durante o período de privação de 14 dias.

\begin{tabular}{lccccc}
\hline Tratamentos & & \multicolumn{2}{c}{ Parâmetros da Qualidade da Água } \\
\hline $\begin{array}{l}\text { Nível de proteína bruta } \\
\text { na ração }(\%)\end{array}$ & Regime alimentar & OD $(\mathrm{mg} / \mathrm{L})$ & $\mathrm{T}\left({ }^{\circ} \mathrm{C}\right)$ & $\mathrm{C}(\mathrm{mS} / \mathrm{cm})$ & $\mathrm{pH}$ \\
\hline \multirow{2}{*}{ T 28} & Com privação & $6,09 \pm 0,26 \mathrm{aA}$ & $27,9 \pm 0,09 \mathrm{aA}$ & $18,3 \pm 0,56 \mathrm{aA}$ & $4,8 \pm 0,10 \mathrm{aA}$ \\
& Sem privação & $4,7 \pm 0,21 \mathrm{aB}$ & $27,0 \pm 0,02 \mathrm{aA}$ & $21,8 \pm 0,57 \mathrm{aB}$ & $5,1 \pm 0,11 \mathrm{aA}$ \\
\hline \multirow{2}{*}{ T32 } & Com privação & $6,0 \pm 0,43 \mathrm{aA}$ & $27,1 \pm 0,08 \mathrm{aA}$ & $18,7 \pm 0,41 \mathrm{aA}$ & $4,9 \pm 0,34 \mathrm{aA}$ \\
& Sem privação & $4,8 \pm 0,14 \mathrm{aB}$ & $26,9 \pm 0,03 \mathrm{aA}$ & $23 \pm 0,98 \mathrm{aB}$ & $5,2 \pm 0,18 \mathrm{aA}$ \\
\hline \multirow{2}{*}{ T 36 } & Com privação & $6,4 \pm 0,1 \mathrm{aA}$ & $27,0 \pm 0,09 \mathrm{aA}$ & $18,4 \pm 0,44 \mathrm{aA}$ & $4,9 \pm 0,18 \mathrm{aA}$ \\
& Sem privação & $4,9 \pm 0,31 \mathrm{aB}$ & $27,0 \pm 0,04 \mathrm{aA}$ & $23,2 \pm 0,54 \mathrm{aB}$ & $5,2 \pm 0,09 \mathrm{aA}$ \\
\hline \multirow{2}{*}{ T 40 } & Com privação & $6,2 \pm 0,23 \mathrm{aA}$ & $27,0 \pm 0,01 \mathrm{aA}$ & $18,4 \pm 0,86 \mathrm{aA}$ & $4,8 \pm 0,15 \mathrm{aA}$ \\
& Sem privação & $4,9 \pm 0,16 \mathrm{aB}$ & $27,0 \pm 0,06 \mathrm{aA}$ & $22,6 \pm 1,26 \mathrm{aB}$ & $5,1 \pm 0,10 \mathrm{aA}$ \\
\hline
\end{tabular}

(1) Médias ( \pm desvio-padrão) seguidas de mesma letra , minúscula para concentração de

proteína bruta na ração e maiúscula para regime alimentar, não diferem entre si pelo

teste de Tukey, a $5 \%$ de probabilidade.

(1) Means ( \pm standard- desviation) followed by the same kleine letter for crude protein content in feed and capital letter for feed regime have no diference by Tukey test $(p<0,05)$.

Tabela 3 - Oxigênio dissolvido (OD), temperatura (T), condutividade (C) e pH da água durante o período de realimentação de 46 dias.

\begin{tabular}{lccccc}
\hline Tratamentos & & \multicolumn{4}{c}{ Parâmetros da Qualidade da Água } \\
\hline $\begin{array}{l}\text { Nível de proteína } \\
\text { bruta na ração (\%) }\end{array}$ & Regime alimentar & OD $(\mathrm{mg} / \mathrm{L})$ & $\mathrm{T}\left({ }^{\circ} \mathrm{C}\right)$ & $\mathrm{C}(\mathrm{mS} / \mathrm{cm})$ & $\mathrm{pH}$ \\
\hline \multirow{2}{*}{ T 28} & Com privação & $5,7 \pm 0,10 \mathrm{aA}$ & $27,1 \pm 0,08 \mathrm{aA}$ & $22,9 \pm 1,00 \mathrm{aA}$ & $5,1 \pm 0,10 \mathrm{aA}$ \\
& Sem privação & $5,7 \pm 0,22 \mathrm{aA}$ & $27,2 \pm 0,07 \mathrm{aA}$ & $22,0 \pm 0,69 \mathrm{aA}$ & $5,0 \pm 0,11 \mathrm{aA}$ \\
\hline \multirow{2}{*}{ T32 } & Com privação & $5,8 \pm 0,18 \mathrm{aA}$ & $27,0 \pm 0,09 \mathrm{aA}$ & $26,3 \pm 2,47 \mathrm{abA}$ & $5,3 \pm 0,34 \mathrm{bA}$ \\
& Sem privação & $5,7 \pm 0,04 \mathrm{aA}$ & $27,0 \pm 0,06 \mathrm{aA}$ & $26,0 \pm 2,38 \mathrm{abA}$ & $5,3 \pm 0,18 \mathrm{bA}$ \\
\hline \multirow{2}{*}{ T36 } & Com privação & $5,8 \pm 0,26 \mathrm{aA}$ & $27,1 \pm 0,04 \mathrm{aA}$ & $27,0 \pm 3,25 \mathrm{bA}$ & $5,2 \pm 0,18 \mathrm{bA}$ \\
& Sem privação & $5,5 \pm 0,27 \mathrm{aA}$ & $27,0 \pm 0,02 \mathrm{aA}$ & $28,6 \pm 3,53 \mathrm{bA}$ & $5,4 \pm 0,09 \mathrm{bA}$ \\
\hline \multirow{2}{*}{ T 40} & Com privação & $5,6 \pm 0,26 \mathrm{aA}$ & $27,0 \pm 0,07 \mathrm{aA}$ & $31,1 \pm 2,29 \mathrm{bA}$ & $5,4 \pm 0,15 \mathrm{bA}$ \\
& Sem privação & $5,7 \pm 0,25 \mathrm{aA}$ & $27,1 \pm 0,07 \mathrm{aA}$ & $28,1 \pm 3,91 \mathrm{bA}$ & $5,3 \pm 0,10 \mathrm{bA}$ \\
\hline
\end{tabular}

(1) Médias ( \pm desvio-padrão) seguidas de mesma letra, minúscula para concentração de proteína bruta na ração e maiúscula para regime alimentar, não diferem entre si pelo teste de Tukey, a $5 \%$ de probabilidade.

(1) Means ( \pm standard- desviation) followed by the same kleine letter for crude protein content in feed and capital letter for feed regime have no diference by Tukey test $(p<0,05)$.

Tabela 4 - Peso médio inicial (PM), peso médio final da privação (PM), taxa de crescimento específico (TCE) e ganho de peso relativo (GPR) de juvenis de tambaqui (Colossoma macropomum) submetidos a ração com quatro concentrações de proteína bruta e dois regimes alimentares, ao final do período de privação alimentar.

\begin{tabular}{lccccc}
\hline Tratamentos & \multicolumn{4}{c}{ Parâmetros Zootécnicos } \\
\hline $\begin{array}{l}\text { Nível de proteína } \\
\text { bruta na ração (\%) }\end{array}$ & Regime alimentar & PM inicial $(\mathrm{g})$ & $\begin{array}{c}\text { PM Final } \\
\text { da privação }(\mathrm{g})\end{array}$ & $\begin{array}{c}\text { TCE } \\
(\%)\end{array}$ & $\begin{array}{c}\text { GPR } \\
(\%)\end{array}$ \\
\hline \multirow{2}{*}{ T 28} & Com privação & $50,1 \pm 0,15 \mathrm{a}$ & $47,3 \pm 0,67 \mathrm{aA}$ & $-0,42 \pm 0,11 \mathrm{aA}$ & $-5,7 \pm 1,45 \mathrm{aA}$ \\
& Sem privação & $50,4 \pm 0,37 \mathrm{a}$ & $64,5 \pm 2,70 \mathrm{aB}$ & $1,76 \pm 0,25 \mathrm{aB}$ & $28,01 \pm 4,56 \mathrm{aB}$ \\
\hline \multirow{2}{*}{ T32 } & Com privação & $50,2 \pm 0,17 \mathrm{a}$ & $48,3 \pm 0,23 \mathrm{abA}$ & $-0,27 \pm 0,05 \mathrm{abA}$ & $-3,78 \pm 0,70 \mathrm{abA}$ \\
& Sem privação & $50,3 \pm 0,19 \mathrm{a}$ & $66,7 \pm 3,17 \mathrm{abB}$ & $2,00 \pm 0,33 \mathrm{abB}$ & $32,42 \pm 6,22 \mathrm{abB}$ \\
\hline \multirow{2}{*}{ T36 } & Com privação & $50,1 \pm 0,27 \mathrm{a}$ & $48,0 \pm 0,54 \mathrm{abA}$ & $-0,30 \pm 0,08 \mathrm{abA}$ & $-4,21 \pm 1,14 \mathrm{abA}$ \\
& Sem privação & $50,2 \pm 0,18 \mathrm{a}$ & $69,7 \pm 3,42 \mathrm{abB}$ & $2,32 \pm 0,36 \mathrm{abB}$ & $38,66 \pm 7,12 \mathrm{abB}$ \\
\hline \multirow{2}{*}{ T40 } & Com privação & $50,1 \pm 0,21 \mathrm{a}$ & $47,6 \pm 0,24 \mathrm{bA}$ & $-0,37 \pm 0,05 \mathrm{bA}$ & $-5,1 \pm 0,69 \mathrm{bA}$ \\
& Sem privação & $50,6 \pm 0,31 \mathrm{a}$ & $73,4 \pm 1,91 \mathrm{bB}$ & $2,64 \pm 0,22 \mathrm{bB}$ & $44,8 \pm 4,52 \mathrm{bB}$ \\
\hline
\end{tabular}

quantidades de proteínas são mobilizadas (Sheridan \& Mommsen, 1991). No entanto, a tendência geral entre as espécies é conservar a proteína corporal, utilizando-se dos estoques de lipídeos e glicogênio (Souza et al., 2000a).
Após o período de privação alimentar, os peixes desenvolvem mecanismos capazes de reverter processos de mobilização das reservas para suprir o catabolismo. Na fase de realimentação, primeiramente, eles utilizam o alimento 
para superar as necessidades energéticas para manutenção dos processos vitais e para repor o catabolismo do tecido. Somente a partir dessa condiçâao satisfeita, o destino da dieta será para o crescimento (Hepher, 1988).

No presente estudo, o período de realimentação de 46 dias, fase em que os peixes que estavam sob privaçáo alimentar voltaram a ser alimentados, os índices zootécnicos avaliados mostraram diferenças entre as raçôes testadas e entre os regimes adotados (Tabela 5). As variaçôes ocorridas nesse período foram avaliadas para testar principalmente o ganho de peso compensatório, por meio da taxa de crescimento e da eficiência alimentar dos peixes submetidos à privação, assim também para avaliar a hiperfagia em funçáo do consumo diário de ração e a composiçáo corporal dos peixes em funçáo dos tratamentos.

A taxa de crescimento específico, o ganho de peso relativo e a eficiência alimentar dos peixes submetidos à privação alimentar foram maiores comparadas ao tratamento sem privação alimentar, e o melhor desempenho produtivo foi encontrado com a ração contendo $36 \%$ de proteína bruta. O consumo diário de ração também aumentou nos peixes submetidos aos tratamentos com privação alimentar, principalmente naqueles alimentados com ração de $28 \%$ de proteína bruta ou maior relação energia/proteína.
O consumo de proteína bruta náo apresentou diferença $(\mathrm{p}<0,05)$ entre os regimes, porém variou em relação às raçôes fornecidas, pois o consumo aumentou conforme aumentou a concentraçáo protéica. Para a taxa de eficiência protéica, os peixes submetidos à privaçáo tiveram melhor desempenho. Sugere-se entáo, que em função das respostas fisiológicas alteradas na fase de realimentaçáo, os peixes privados de alimentaçáo conseguem aproveitar melhor a proteína do alimento para alcançar a compensaçáo de peso.

Por outro lado, as raçôes com $32 \%$ e $36 \%$ de proteína bruta foram as que proporcionaram melhor taxa de eficiência protéica pelos peixes, sendo observado, também, que a ração contendo $32 \%$ além de ter sido a mais eficiente na taxa de eficiência protéica $(88,3 \%)$, proporcionou consumo de proteína pelos peixes menor, quando comparado à ração com $36 \%$ com a qual os peixes obtiveram taxa de eficiência protéica de $85,8 \%$. Os peixes que se alimentaram com a raçáo com $32 \%$ de proteína bruta conseguiram ter melhor aproveitamento protéico com menor consumo. Esses resultados encontramse na Tabela 6.

Apesar da raçáo com $32 \%$ de proteína bruta ter proporcionado a melhor taxa de eficiência protéica para os peixes, a raçáo com $36 \%$ favoreceu o alcance dos melhores

Tabela 5 - Peso médio final (PM), taxa de crescimento específico (TCE), eficiência alimentar (EA), ganho de peso relativo (GPR) e consumo diário de ração (CDR) de juvenis de tambaqui (Colossoma macropomum) submetidos a ração com quatro concentrações de proteína bruta e dois regimes alimentares, ao final do experimento.

\begin{tabular}{lcccccc}
\hline Tratamentos & \multicolumn{5}{c}{ Parâmetros Zootécnicos } \\
\hline $\begin{array}{l}\text { Nivel de } \\
\text { proteína bruta } \\
\text { na ração }\end{array}$ & $\begin{array}{c}\text { Regime } \\
\text { alimentar }\end{array}$ & PM Final (g) & TCE $(\%)$ & EA (\%) & GPR (\%) & CDR(\%) \\
\hline \multirow{2}{*}{ T 28} & Com privação & $79,17 \pm 3,1 \mathrm{aA}$ & $1,11 \pm 0,10 \mathrm{aA}$ & $28,22 \pm 1,52 \mathrm{~A}$ & $67,37 \pm 8,36 \mathrm{aA}$ & $1,98 \pm 0,041 \mathrm{aA}$ \\
& Sem privação & $83,90 \pm 5,3 \mathrm{aB}$ & $0,56 \pm 0,05 \mathrm{aB}$ & $17,24 \pm 3,47 \mathrm{aB}$ & $29,93 \pm 3,01 \mathrm{aB}$ & $1,97 \pm 0,37 \mathrm{aB}$ \\
\hline \multirow{2}{*}{ T 32 } & Com privação & $93,87 \pm 13,2 \mathrm{bA}$ & $1,42 \pm 0,30 \mathrm{bA}$ & $36,37 \pm 3,12 \mathrm{bA}$ & $94,02 \pm 27,33 \mathrm{bA}$ & $1,77 \pm 0,16 \mathrm{bA}$ \\
& Sem privação & $109,83 \pm 2,7 \mathrm{bB}$ & $1,08 \pm 0,10 \mathrm{bB}$ & $30,66 \pm 0,46 \mathrm{aA}$ & $64,82 \pm 7,7 \mathrm{aA}$ & $1,63 \pm 0,12 \mathrm{bB}$ \\
\hline \multirow{2}{*}{ T 36 } & Com privação & $102,05 \pm 1,91 \mathrm{bA}$ & $1,63 \pm 0,03 \mathrm{bA}$ & $41,38 \pm 1,10 \mathrm{bA}$ & $112,42 \pm 3,08 \mathrm{bA}$ & $1,71 \pm 0,06 \mathrm{bA}$ \\
& Sem privação & $105,54 \pm 10,92 \mathrm{bB}$ & $0,89 \pm 0,28 \mathrm{bB}$ & $32,44 \pm 8,91 \mathrm{bB}$ & $51,79 \pm 19,33 \mathrm{bB}$ & $1,36 \pm 0,07 \mathrm{bB}$ \\
\hline \multirow{2}{*}{ T 40 } & Com privação & $94,68 \pm 3,48 \mathrm{bA}$ & $1,49 \pm 0,07 \mathrm{bA}$ & $38,12 \pm 3,09 \mathrm{bA}$ & $98,84 \pm 6,62 \mathrm{bA}$ & $1,78 \pm 0,09 \mathrm{bA}$ \\
& Sem privação & $118,87 \pm 8,69 \mathrm{bB}$ & $1,04 \pm 0,21 \mathrm{bB}$ & $32,81 \pm 5,54 \mathrm{bB}$ & $62,19 \pm 16,15 \mathrm{bB}$ & $1,50 \pm 0,06 \mathrm{bB}$ \\
\hline
\end{tabular}

(1) Médias ( \pm desvio-padrão) seguidas de mesma letra, minúscula para concentração de proteína bruta na ração e maiúscula para regime alimentar, não diferem entre si pelo teste de Tukey, a $5 \%$ de probabilidade.

${ }^{(1}$ Means ( \pm standard- desviation) followed by the same kleine letter for crude protein content in feed and capital letter for feed regime have no diference by Tukey test $(p<0,05)$.

desempenhos produtivos em termos de eficiência alimentar, ganho de peso relativo, taxa de crescimento específico e maior duraçáo hiperfágica, adquirindo assim a maior sobrecompensaçấo do ganho de peso, com peso médio final dos peixes de $102,05 \mathrm{~g}$, próximo dos peixes que foram continuamente alimentados (Tabela 5).

O fator de condiçáo $(\mathrm{K})$ ao final do experimento demonstrou resultados similares daqueles encontrados no período de privaçáo. Isto revela melhor desempenho dos peixes nos regimes sem restrição, alimentados com as rações de $32 \% \%, 36 \%$ e $40 \%$ PB (Tabela 6). Este fato revela que nem todos os tratamentos proporcionaram tamanhos finais similares, não significando que os peixes menores sejam obrigatoriamente peixes magros, a exemplo do trabalho registrado para tambaqui por Ituassú et al. (2004). Não houve 
Tabela 6 - Consumo de proteína bruta (CPB), taxa de eficiência protéica (TEP), índice hepatossomático (IHS) e fator de condição (K) de juvenis de tambaqui (Colossoma macropomum) submetidos a ração com quatro concentrações de proteína bruta e dois regimes alimentares, ao final do experimento.

\begin{tabular}{lccccc}
\hline Tratamentos & \multicolumn{5}{c}{ Parâmetros Zootécnicos } \\
\hline $\begin{array}{l}\text { Nível de proteína } \\
\text { bruta na ração }\end{array}$ & Regime alimentar & CPB & TEP & IHS & K \\
\hline \multirow{2}{*}{ T 28 } & Com privação & $6,98 \pm 0,35 \mathrm{aA}$ & $72,80 \pm 5,14 \mathrm{aA}$ & $0,31 \pm 0,14 \mathrm{aA}$ & $6,09 \pm 0,16 \mathrm{aA}$ \\
& Sem privação & $7,40 \pm 0,98 \mathrm{aA}$ & $42,69 \pm 10,36 \mathrm{aB}$ & $1,32 \pm 0,85 \mathrm{aA}$ & $6,3 \pm 0,26 \mathrm{aB}$ \\
\hline \multirow{2}{*}{ T32 } & Com privação & $8,27 \pm 2,21 \mathrm{abA}$ & $88,31 \pm 14,74 \mathrm{abA}$ & $080 \pm 0,77 \mathrm{aA}$ & $6,89 \pm 0,64 \mathrm{bA}$ \\
& Sem privação & $9,21 \pm 0,83 \mathrm{abA}$ & $74,94 \pm 1,89 \mathrm{abB}$ & $0,81 \pm 0,80 \mathrm{aA}$ & $7,64 \pm 0,16 \mathrm{bB}$ \\
\hline \multirow{2}{*}{ T 36 } & Com privação & $10,07 \pm 0,55 \mathrm{bA}$ & $85,82 \pm 2,14 \mathrm{bA}$ & $1,20 \pm 0,74 \mathrm{aA}$ & $7,28 \pm 0,08 \mathrm{bA}$ \\
& Sem privação & $8,27 \pm 0,72 \mathrm{bA}$ & $68,62 \pm 20,96 \mathrm{bB}$ & $0,79 \pm 0,85 \mathrm{aA}$ & $7,42 \pm 0,51 \mathrm{bB}$ \\
\hline \multirow{2}{*}{ T 40 } & Com privação & $10,79 \pm 0,68 \mathrm{cA}$ & $69,86 \pm 4,34 \mathrm{bA}$ & $0,70 \pm 0,61 \mathrm{baA}$ & $6,95 \pm 0,18 \mathrm{bA}$ \\
& Sem privação & $11,40 \pm 0,30 \mathrm{cA}$ & $63,57 \pm 12,97 \mathrm{bB}$ & $1,21 \pm 0,48 \mathrm{baA}$ & $8,14 \pm 0,44 \mathrm{bB}$ \\
\hline
\end{tabular}

(1) Médias ( \pm desvio-padrão) seguidas de mesma letra, minúscula para concentração de proteína bruta na ração e maiúscula para regime alimentar, não diferem entre si pelo teste de Tukey, a $5 \%$ de probabilidade.

(1) Means ( \pm standard- desviation) followed by the same kleine letter for crude protein content in feed and capital letter for feed regime have no diference by Tukey test $(p<0,05)$

efeito das raçóes e regimes sobre o índice hepatossomático mostrados na Tabela 6.

A melhor relação energia/proteína encontrada para ganho de peso e taxa de crescimento específico do tambaqui foi na ração de $36 \%$ de proteína bruta, com $9,5 \mathrm{kcal} \mathrm{g}^{-1} \mathrm{ED}$ : $\mathrm{PB}$. Este resultado corrobora o estudo de Abimorad (2004) no cultivo intensivo de tambaqui, pois mesmo com a estratégia alimentar de privação adotada no presente trabalho, não houve maior exigência em proteína para os peixes alcançarem o ganho de peso compensatório. Isso ocorre pela ração de maior concentração protéica náo ter garantido o melhor ganho de peso e melhor crescimento na fase de realimentação.

Segundo a teoria lipostática proposta por Kennedy (1953) quanto maior a entrada de energia, menor será a duraçáo da hiperfagia. No presente estudo, a duraçáo da hiperfagia, observada por meio do consumo diário de raçáo, demonstrou que os peixes submetidos à privação alimentar tiveram maior consumo quando alimentados com a ração de $28 \%$ de proteína bruta (alta relação Energia/Proteína), ingerindo assim grande quantidade de energia, indicando aparentemente menor período hiperfágico.

Contudo, os peixes alimentados com as raçóes contendo 28,32 e $40 \%$ de proteína bruta tiveram aumento no consumo de alimento até a quarta semana, logo após o período de privação. Isso sugere a obtenção do ganho compensatório desses peixes na quarta semana, quando cessou a hiperfagia. Para os peixes alimentados com a ração com $36 \%$ de proteína bruta, o consumo foi aumentando gradativamente até a sexta semana, prolongando desta maneira a duração hiperfágica e assim os peixes adquiriram o melhor ganho de peso compensatório (Figura 1).

Considerando que a proteína é o nutriente mais caro na composição de raçôes para peixes, Lovell (1989) afirma que as raçóes comerciais devem conter o mínimo necessário deste nutriente, com balanceamento de aminoácidos essenciais para garantir adequado crescimento aos animais. Isto sugere que raçôes contendo uma relação $\mathrm{E} / \mathrm{P}$ com níveis de proteína adequados à exigência da espécie seriam suficientes para reduzir os custos de produção e ao mesmo tempo proporcionar melhor desempenho zootécnico para os peixes. Contudo, a exigência protéica está diretamente relacionada ao nível de proteína na dieta, à qualidade desta proteína e, sobretudo, ao consumo protéico (Abimorad, 2004).

A composição corporal não revelou diferenças significativas $(\mathrm{P}>0,05)$ para as porcentagens de umidade, cinzas e proteínas nos tratamentos designados, porém foram detectadas influências visíveis $(\mathrm{P}<0,05)$ sobre os níveis de extrato etéreo (EE) nas amostras. No entanto, comparando-se os resultados das análises da composição corporal dos peixes, do início do experimento, com os resultados obtidos ao final da pesquisa,

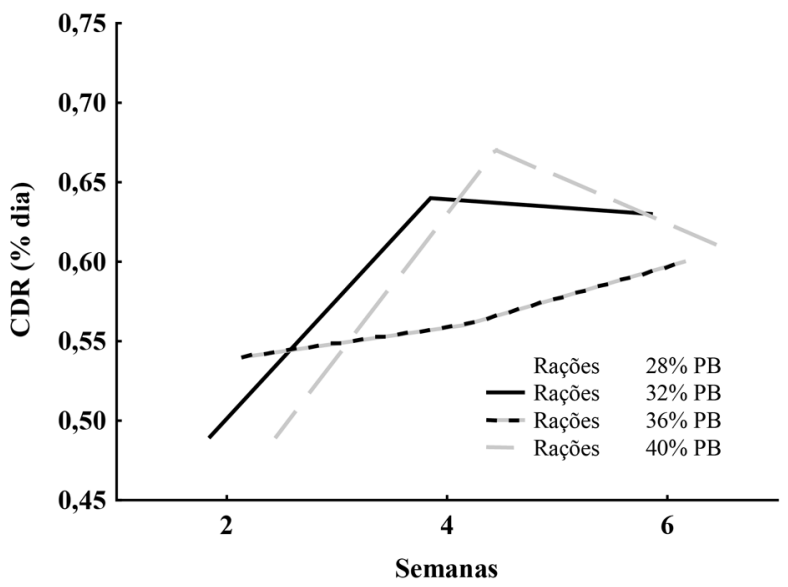

Figura 1- Consumo diário de ração (CDR\%) por período quinzenal dos peixes alimentados com níveis crescentes de proteína bruta, mostrando a duração da hiperfagia. 
observou-se a diminuiçáo dos valores de cinzas e umidade na carcaça dos peixes e o aumento de extrato etéreo (EE) e proteína corporal em todos os tratamentos (Tabela 7).

O aumento da deposição de proteína corporal ao final do experimento pode estar relacionado ao tipo de manejo alimentar de privação, como também a frequência alimentar. Segundo Ituassú et al. (2004), demonstraram em seus estudos com tambaqui que o período de privaçáo influenciou as porcentagens de proteína, aumentando os teores de proteína na carcaça, conforme o aumento dos dias de privação. $\mathrm{O}$ período de 14 dias de privação não prejudicou a qualidade da carcaça do tambaqui.

Assim sendo, o teor de proteína bruta na carcaça do tambaqui mesmo não apresentando variaçôes significativas em relação aos tratamentos, houve incremento maior em todos os peixes que foram privados de alimentaçáo e naqueles realimentados com as raçôes contendo os maiores níveis protéicos (36 e 40\%PB) (Tabela 7). Este aumento no percentual de proteína da carcaça, em relação ao início do experimento, sugere que o tambaqui apresenta habilidade para ajustes metabólicos após 46 dias de realimentação, conseguindo aumento na deposição de músculo.

Segundo Van der Meer et al. (1995), ao avaliarem a composição corporal do tambaqui, observaram que o teor de lipídeo corporal está relacionado com as variaçóes na composição das dietas, tendo como expectativa o aumento do nível de lipídeo do corpo de acordo com o nível de lipídeo da dieta.

$\mathrm{O}$ acúmulo de grandes quantidades de gordura corporal em tambaquis alimentados com dietas com baixos teores de proteína têm sido reportado por esses pesquisadores. Por outro lado, quando a concentração de proteína da dieta está acima das exigências da espécie, náo há aumento significante do conteúdo de lipídios do corpo, assim como a conversão de aminoácidos nos lipídios depositados têm eficiência energética de apenas 53\% (Black \& Love, 1986). Portanto, um aumento no nível de proteína na dieta até $36 \%$, pode ser estratégia segura para produção de peixe magro.

O lipídeo da carcaça dos peixes, sob restrição de alimento, que foram realimentados com a ração com $36 \%$ de $\mathrm{PB}$, mesmo apresentando menores porcentagens apresentou relativo incremento em relaçáo aos peixes alimentados continuamente com esta ração. Portanto, este incremento de gordura e a maior deposição de proteína corporal mostradas na Tabela 7, podem justificar o melhor ganho de peso compensatório, maior duraçáo da hiperfagia, melhor taxa de crescimento e eficiência alimentar dos peixes alimentados com esta ração.

\section{CONCLUSÕES}

Juvenis de tambaqui, submetidos à privação alimentar, apresentam crescimento compensatório quando realimentados.

A privação alimentar pode ser usada na prática da criação desta espécie.

Juvenis de tambaqui apresentam melhor desempenho, melhor composição de carcaça e maior duração da hiperfagia quando alimentados com $36 \%$ de proteína bruta na raçáo após à privação alimentar.

Juvenis de tambaqui não aumentam suas exigências em proteína após período de privaçáo alimentar.

\section{AGRADECIMENTOS}

À Fundação de Amparo a Pesquisa do Estado do Amazonas - FAPEAM, pelo apoio financeiro;

Tabela 7 - Percentuais de umidade, cinzas, extrato etéreo e proteína bruta de juvenis de tambaqui (Colossoma macropomum) submetidos a ração com quatro concentrações de proteína bruta e dois regimes alimentares.

\begin{tabular}{lccccc}
\hline Tratamentos & & \multicolumn{2}{c}{ Parâmetros Zootécnicos } \\
\hline $\begin{array}{l}\text { Nível de proteína bruta } \\
\text { na ração }\end{array}$ & Regime alimentar & Umidade & Cinzas & Extrato etéreo (\%) & Proteína Bruta(\%) \\
\hline \multirow{2}{*}{ T 28 } & Com privação & $78,6 \pm 1,87 \mathrm{aA}$ & $10,7 \pm 1,90 \mathrm{aA}$ & $28,3 \pm 0,45 \mathrm{aA}$ & $57,6 \pm 2,34 \mathrm{aA}$ \\
& Sem privação & $76,9 \pm 0,52 \mathrm{aA}$ & $10,2 \pm 0,36 \mathrm{aA}$ & $29,3 \pm 0,23 \mathrm{aB}$ & $57,5 \pm 1,05 \mathrm{aA}$ \\
\hline \multirow{2}{*}{ T 32 } & Com privação & $78,4 \pm 0,75 \mathrm{aA}$ & $10,7 \pm 0,45 \mathrm{aA}$ & $28,1 \pm 1,25 \mathrm{aA}$ & $59,9 \pm 3,86 \mathrm{aA}$ \\
& Sem privação & $76,9 \pm 1,85 \mathrm{aA}$ & $9,6 \pm 0,45 \mathrm{aA}$ & $29,9 \pm 2,20 \mathrm{aB}$ & $57,0 \pm 1,36 \mathrm{aA}$ \\
\hline \multirow{2}{*}{ T 36 } & Com privação & $77,8 \pm 1,13 \mathrm{aA}$ & $10,4 \pm 0,72 \mathrm{aA}$ & $25,7 \pm 0,61 \mathrm{bA}$ & $61,1 \pm 1,15 \mathrm{aA}$ \\
& Sem privação & $77,3 \pm 2,15 \mathrm{aA}$ & $11,1 \pm 1,15 \mathrm{aA}$ & $24,4 \pm 0,36 \mathrm{BB}$ & $60,8 \pm 2,25 \mathrm{aA}$ \\
\hline T 40 & Com privação & $80,5 \pm 2,57 \mathrm{aA}$ & $12,1 \pm 0,73 \mathrm{aA}$ & $22,9 \pm 2,21 \mathrm{bA}$ & $62,4 \pm 2,91 \mathrm{aA}$ \\
& Sem privação & $78,3 \pm 1,43 \mathrm{aA}$ & $10,1 \pm 0,76 \mathrm{aA}$ & $28,36 \pm 2,53 \mathrm{bB}$ & $59,03 \pm 1,79 \mathrm{aA}$ \\
\hline \multirow{2}{*}{ INICIAL } & & 80,3 & 13,3 & 24,4 & 53,7
\end{tabular}

(1)Médias seguidas de mesma letra, minúscula para concentração de proteína bruta na ração e maiúscula para regime alimentar, não diferem entre si pelo teste de Tukey, a 5\% de probabilidade

(1) Means ( \pm standard- desviation) followed by the same kleine letter for crude protein content in feed and capital letter for feed regime have no diference by Tukey test $(p<0,05)$

${ }^{*}$ Análise centesimal dos peixes no início do experimento

* Fish proximate analyses when experiment start. 
Ao $\mathrm{CNPq}$, pelo apoio financeiro que possibilitou a pela bolsa concedida.

\section{BIBLIOGRAFIA CITADA}

Abimorad, E.G. 2004. Relation between levels of protein and energy digestibilities diets with different proportions of lipids and carbohydrates for the growth of pacu, Piaractus mesopotamicus. Dissertação de Mestrado, Universidade Estadual Paulista, Jaboticabal. $89 \mathrm{p}$ (in portuguese).

Ayres, M.; Ayres junior, M.; Ayres, D.L.; Santos, A.S.D. 2007. BioEstat 5.0: Statistical Applications in the areas of biological and medical sciences. Belém: Sociedade Civil Mamirauá, Brasilia, CNPq. 339p (in portuguese).

Araújo-lima, C.A.R.M; Goulding, M. 1998. The fruits of tambaqui: Ecology, Conservation and cultivation in the Amazon.Tefé: Civil Society Mamirauá Brasília: CNPq. 186p (in portuguese).

Black, D; Love, R. M. 1986. The sequential mobilisation and restoration of energy reserves in tissues of atlantic cod during starvation and refeeding. J. Comp. Physiol, 156:469-479.

Gaylord, T. G.; Gatlin iii, D. M. 2001. Dietary protein and energy modifications to maximize compensatory growth of channel catfish (Ictalurus punctatus). Aquaculture, 194:337-348.

Hornick, J. L.; Van eenaeme, C.; Gérard, O.; Dufrasne, I.; Istasse, L. 2000. Mechanisms of reduced and compensatory growth. Domestic Animal Endocrinology, 9:121-132.

HEPHER, B. 1998. Nutrition of pond fishes. 1988. Cambridge: Cambridge University Press, 387p.

Ituassú, D.R; Santos, G.R.R.; Roubach, R.; Pereira-filho, M. 2004. Growth of tambaqui submitted to different feed deprivation periods. Pesquisa Agropecuária Brasileira. 39:1199-1203(in portuguese).

Jobling, M.; Jorgensen, E. H; Siikavuopio, S. I. 1993. The influence of previous feeding regime on the compensatory growth response of maturing and immature Arctic charr, Salvelinus alpinus. Journal of Fish Biology, 43:409-419.

Kubitza, F. 2003. Water quality in the cultivation of fish and shrimp. Jundiaí, 229p (in portuguese).

Kennedy, G.C. 1953. The role of depot fat in hypothalalmic control of food intake in the rat. Proceedings of the Royal Society B, 140:578-592.

Lovell, R.T.1989. Nutrition and feeding of fish. New York: Van Nostrand Reinhold, 260p.
Metcalfe, N. B; Monaghan, P. 2001. Compensation for a bad start: grow now, pay later. Trends in Ecology and Evolution, 16: 255260.

Nicieza, A.G; Metcalfe, N.B.1997. Growth compensatory in juvenile Atlantic Salmon: Responses to depressed temperature and food availability. Ecology,78:2385-2400.

Ono, E.A. 2005. Cultivar peixes na Amazônia: Possibilidade ou utopia? Panorama da Aqüicultura, 15:41-48.

Pezzato, L.E. 2005. Fish feeding - Cost and benefit. Disponível em: $<$ htt:// www.sbz.org.br/ eventos/ Porto Alegre/ homepagesbz/ Pezzato.htm. Acesso em: 21 de novembro (in portuguese).

Rotta, M. A. 2002. Use of energy and protein for fish, Corumbá: Embrapa Pantanal. 24p (in portuguese).

Sheridan, M. A; Mommsen, T. P. 1991. Effects of nutritional satate on in vivo lipid and carbohydrate metabolism of coho salmon, Oncorhynchus kisutch. Gen. Comp. Endocrinol, 81:473-483.

Souza, V. L.; Oliveira, E. G.; Urbinati, E. C. 2000. Effects of food restriction and refeeding on energy stores and growth of pacu, Piaractus mesopotamicus (Characidae). Journal of Aquaculture in the Tropics, 15, n.4:371- 379 .

Val, A.L.; Honczaryk, A. 1995. Creating fish in the Amazon. Instituto de Pesquisa da Amazônia, Manaus, Amazonas, Brasil.149p (in portuguese).

Van der meer, M. B; Machiels, M. A. M; Verdegem, M. C. J. 1995. The effect of Dietary protein level on grwoth, protein utilization and body composition of Colossoma macropomum. Aquaculture research, 26: 901-909.

Wang, Y.; Cui, Y.; Yang, Y.; Cai, F. 2000. Compensatory growth in Hybrid tilapia, Oreochromis mossambicus $x$ O. niloticus, reared in sea water. Aquaculture, 189:101-108.

Xie, S.; Zhu, X.; Cui, Y.; Wootton, R.J.; Lei, W.; Yang, Y. 2001. Compensatory growth in the gibel carp following feed deprivation: temporal patterns in growth, nutrient deposition, feed intake and body composition. Journal of Fish Biology, 58: 999-1009.

Zar, J.H.1996. Biostatistical analysis. Upper Saddle River: Prentice Hall, 699p.

Recebido em 09/09/2009

Aceito em 12/02/2010 